\section{RMD Open}

Rheumatic \&

Musculoskeletal Diseases

\title{
Pathogenesis of ischaemic and non- ischaemic heart diseases in rheumatoid arthritis
}

\author{
Przemysław Błyszczuk (D) , 1,2 Zoltan Szekanecz ${ }^{3}$
}

To cite: Błyszczuk $P$, Szekanecz Z. Pathogenesis of ischaemic and nonischaemic heart diseases in rheumatoid arthritis. RMD Open 2020;6:e001032. doi:10.1136/ rmdopen-2019-001032

Received 29 August 2019 Revised 17 November 2019 Accepted 22 November 2019

\section{Check for updates}

\section{(C) Author(s) (or their} employer(s)) 2020. Re-use permitted under CC BY-NC. No commercial re-use. See rights and permissions. Published by BMJ.

${ }^{1}$ Center of Experimental Rheumatology, University of Zurich, Schlieren, Switzerland ${ }^{2}$ Department of Clinical Immunology, Jagiellonian University Medical College, Cracow, Poland

${ }^{3}$ Department of Rheumatology, University of Debrecen, Faculty of Medicine, Debrecen, Hungary

Correspondence to Dr Przemysław Błyszczuk; przemyslaw.blyszczuk@uzh.ch

\section{ABSTRACT}

Rheumatoid arthritis (RA) is characterised by a chronic inflammatory condition of the joints, but the comorbidities of RA predominantly contribute to the reduced lifespan associated with this disease. Clinical data indicate that cardiovascular disease is the major comorbidity associated with mortality in RA. In this review, we aimed to describe the pathogenesis of heart failure in RA. First, we emphasised the fundamental differences between ischaemic and non-ischaemic heart diseases and referred to their relevance in excessive cardiovascular-dependent mortality in RA. Second, we highlighted aspects of asymptomatic changes in cardiac tissue and in coronary blood vessels that are commonly found in patients with diagnosed RA. Third, we focused on high-grade systemic inflammation as a key trigger of ischaemic and non-ischaemic heart diseases in RA, and described the implication of conventional and biologic antirheumatic medications on the development and progression of heart disease. In particular, we discussed the roles of tumour necrosis factor-alpha (TNF- $\alpha$ ) and anti-TNF- $\alpha$ therapies on the development and progression of ischaemic and nonischaemic heart diseases in RA.

\section{INTRODUCTION}

Rheumatoid arthritis (RA) refers to an autoimmune disease of the joints that affects $0.5 \%-$ $1.0 \%$ of the global population. In this disease, virtually all joints, but typically of hands, feet and knees become inflamed, causing stiffness, pain and eventually destruction of bone and cartilage. RA is not limited to joints but often affects internal organs. These extra-articular comorbidities are responsible for a reduced life expectancy. Patients with RA have approximately a $50 \%$ increased risk of incident cardiovascular events ${ }^{1}$ and cardiovascular death. ${ }^{2}$ However, it should be acknowledged that in some countries, the cardiovascular mortality in the RA population has been significantly reduced in recent times. ${ }^{34}$

Heart diseases that commonly occur in RA can be classified into two major categories (figure 1). One category refers to ischaemic heart diseases, known also as coronary

\section{Key messages}

Patients with rheumatoid arthritis (RA) are at increased risk of developing ischaemic and nonischaemic heart diseases.

- Subclinical pathological changes in heart muscle and in coronary microcirculation are common in RA.

- High-grade systemic inflammation in RA is an important cardiac risk factor.

- Conventional and biologic antirheumatic medications may result in beneficial or adverse effects on cardiovascular outcomes.

heart diseases, which result in insufficient blood supply to the heart muscle by coronary arteries, a pathogenic condition termed coronary artery disease. Mechanistically, in the process of atherosclerosis, atherosclerotic plaques narrow the lumen of arteries, causing a reduction in blood flow. A rupture of atherosclerotic plaques can cause formation of blood clots that may locally block coronary blood vessels and lead to acute coronary syndrome. Insufficient oxygen supply to the myocardium may cause dysfunction or death of cardiomyocytes, cells responsible for the contractile activity of the heart muscle. Clinical manifestations of coronary heart disease are related to the extent of ischaemia. In a less acute form, reduced blood supply may result in angina, cardiomyopathy or arrhythmias. In a more acute form, complete occlusion of larger arteries may cause myocardial infarction and sudden cardiac death.

Heart abnormalities occurring in the absence of coronary artery disease are referred to as non-ischaemic heart diseases. Typically, non-ischaemic heart diseases develop slowly over time and are associated with changes in cellular composition and architecture of the cardiac muscle. Cardiomyopathies represent the most common type of non-ischaemic heart disease, in which ventricles become enlarged and stiff. In the case of dilated 


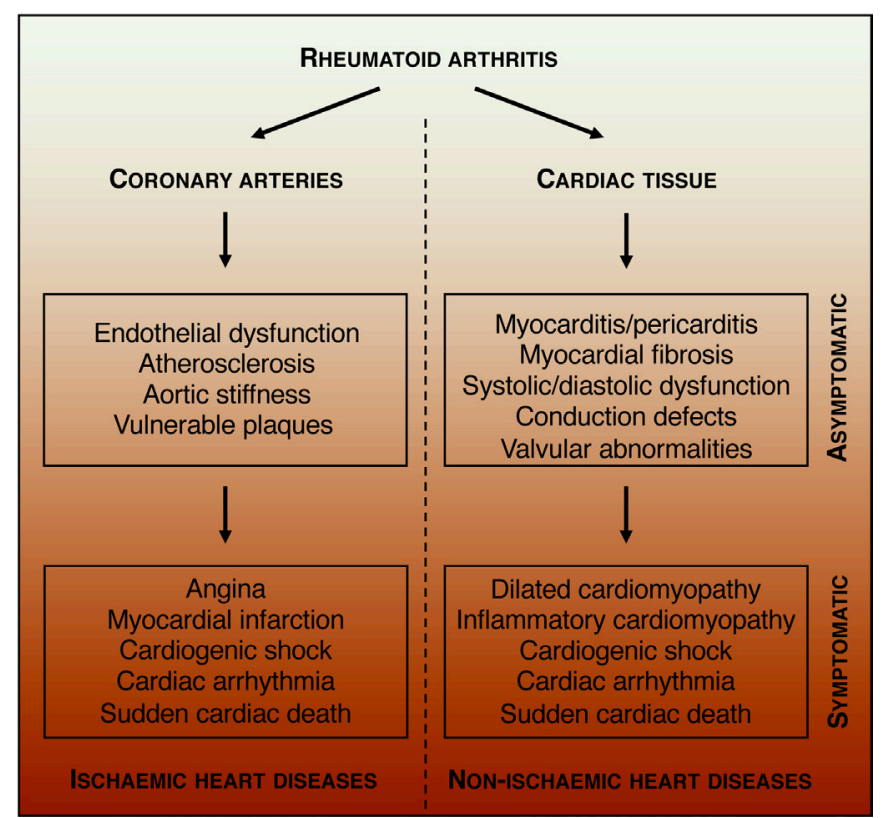

Figure 1 Schematic presentation of the development of ischaemic and non-ischaemic heart diseases in rheumatoid arthritis.

cardiomyopathy, disease can be triggered by intracardiac or extracardiac factors. Dilated cardiomyopathy is often progressive and eventually requires heart transplantation at the end stage of disease. Patients with dilated cardiomyopathy develop not only left ventricular or biventricular dilatation associated with systolic dysfunction, but also heart valve problems, blood clots and arrhythmias leading to heart and secondary organ failure. The phenotype of dilated cardiomyopathy can be a consequence of the ongoing inflammatory processes in the myocardium, termed myocarditis. Inflammation in the heart can also affect the pericardium (pericarditis) and cause excessive accumulation of fluid that may progress into a lifethreating condition, 'cardiac tamponade', demonstrated by an acute loss of ventricular function due to cardiogenic shock. All these acquired pathogenic conditions of the cardiovascular system can occur in patients with RA.

\section{CARDIAC INVOLVEMENT IN RA}

\section{Subclinical changes in hearts of patients with RA}

The majority of patients with RA develop no serious cardiac manifestations for many years. Nevertheless, their hearts can show subclinical and asymptomatic changes. Various non-invasive imaging tools provide accurate insight into the structure and function of the cardiovascular system. Technical advantages and limitations of the specific imaging techniques are described elsewhere. ${ }^{5}$ Data of cardiac MRI and positron emission tomography-computed tomography (PET-CT) in patients with RA with no diagnosis of cardiovascular disease demonstrated that up to half showed signs of cardiac fibrosis or inflammation. ${ }^{6} 7$ These changes in the myocardium might be responsible for the observed increased left ventricular mass in patients with RA. ${ }^{8}$ Although hearts of patients with RA typically show effective pumping, the contractile function is often compromised. Reduced systolic and diastolic left ventricle functions were found in up to $50 \%$ of patients with RA without clinical signs of cardiac disease. ${ }^{9}{ }^{10}$ Furthermore, echocardiography studies revealed that RA is also associated with exceptionally high rates of asymptomatic pericarditis and cardiac valvular involvement. ${ }^{11}$

RA causes subclinical changes also in the coronary microcirculation. ${ }^{12}$ Measurements of myocardial flow reserve showed that a third of patients with RA without clinical cardiovascular episodes developed cardiac microvascular dysfunction. ${ }^{13}$ Furthermore, in the absence of coronary artery disease, patients with RA showed higher prevalence, extent and severity of all types of coronary plaques measured by CT angiography. ${ }^{14}$ Of note, patients with RA are twice as likely to experience episodes of silent (unrecognised) myocardial infarction. ${ }^{15}$ These subclinical changes in the myocardium and in the coronary system of patients with RA might be responsible for serious ischaemic and non-ischaemic complications on follow-up.

\section{Clinical manifestations of heart failures in RA}

By the time of RA onset, a history of heart failure is not more common in the RA population, and only patients with new-onset RA are at increased risk of developing ischaemic and non-ischaemic heart diseases. ${ }^{16}$ Furthermore, the clinical presentation of heart failure in RA is different from that of the non-RA population. In cases of incident heart failure, patients with RA show significantly higher mortality despite better cardiac function and lower blood pressure. ${ }^{17}$

Ischaemic heart disease is an important cause of cardiovascular death in patients with RA. ${ }^{18}$ The risk of arterial (including peripheral and coronary) disease or myocardial infarction in RA is comparable to that in diabetes mellitus. ${ }^{19}{ }^{20}$ The incidence of myocardial infarction was $70 \%$ higher than that in the general population and corresponded with the incidence of myocardial infarction in 10-year-older non-RA subjects. ${ }^{19}$ Following myocardial infarction, patients with RA have poorer long-term outcomes compared with individuals without $\mathrm{RA}^{21}$ and a higher risk of death at 30 days. ${ }^{22}$ Patients with RA have a twofold increased risk of sudden cardiac death but are less likely to report symptoms of angina. ${ }^{15}$ In the general population, sudden cardiac death is usually caused by fatal arrhythmias, which is a result of electrophysiological abnormalities in the heart. Patients with early arthritis show no increase in incidence of prolonged QTc interval, an indicator of arrhythmogenic phenotype. ${ }^{23} 24$ Over time, patients with RA progressively develop proarrhythmic QTc prolongation; however, this is not associated with cardiovascular mortality in these patients. ${ }^{23}$

In RA, the incidence of non-ischaemic heart failure is at least as common as the incidence of ischaemic heart failure. ${ }^{1625}$ It has been suggested that the increased 
incidence of non-ischaemic heart failure is mainly responsible for the excess mortality in patients with RA. $^{25}$ However, it remains to be identified which of the nonischaemic heart failure conditions are more prevalent in patients with RA.

\section{TRADITIONAL CARDIOVASCULAR RISK FACTORS IN RA}

Development of cardiovascular morbidity and mortality is dependent on traditional risk factors, such as age, gender, hypertension, diabetes, hyperlipidaemia, smoking, obesity, physical inactivity, personal cardiac history and genetics. Traditional cardiovascular risk factors (except smoking and physical activity) are generally similarly prevalent in patients with RA and in the global population. ${ }^{26}$ Diagnosed hypertension or type 2 diabetes is associated with a nearly twofold increased risk of cardiovascular morbidity in patients with RA. ${ }^{27}$ Surprisingly, the impact of certain traditional risk factors (eg, male gender, smoking, personal cardiac history or physical inactivity) on major cardiovascular outcomes is lower in RA compared with non-RA cohorts. ${ }^{26}{ }^{27}$ Furthermore, an increased cardiovascular incidence in patients with RA has been reported for traditional low-risk factors such as low cholesterol levels ${ }^{28}$ or low body mass index. ${ }^{29}$ These paradoxical observations suggest that different pathogenic mechanisms are responsible for cardiovascular morbidity and mortality among patients with RA compared with the general population.

\section{INFLAMMATION AS A DRIVING FORCE FOR HEART DISEASES IN RA}

It is widely believed that in RA, a high-grade inflammation is a key trigger of a cascade of pathogenic events leading to life-threatening cardiovascular disease in some patients. Clinical data confirmed that systemic inflammation, indicated by elevated serum levels of $\mathrm{C}$ reactive protein (CRP) at baseline, is an independent prognostic biomarker of cardiovascular death in patients with RA. ${ }^{30}$ In fact, each period of increased disease activity in the joints significantly increases cardiovascular risk by $7 \%,{ }^{31}$ whereas a low disease activity reduces the risk of the first cardiovascular event. ${ }^{32}$ At the molecular level, proinflammatory cytokines tumour necrosis factor-alpha (TNF- $\alpha$ ), interleukin (IL)-1 $\beta$, IL-6 and IL-17 have been associated with inflammation in RA and with pathogenesis of heart disease.

\section{Inflammation and ischaemic heart diseases}

Atherosclerosis is associated with local inflammation in the vessel wall and can be enhanced by systemic inflammation. Under homeostatic conditions, vascular function is maintained by the endothelium, producing vasoactive factors, such as nitric oxide. Inflammation reduces the bioavailability of nitric oxide and promotes generation of reactive oxygen species. Furthermore, various inflammatory mediators decrease endothelial barrier function and upregulate production of chemokines and adhesion molecules that tether and recruit circulating leucocytes to promote formation of atherosclerotic plaques. It has been postulated that chronic inflammation is implicated in the development of atherosclerosis in patients with RA. Measurements of carotid intima-media thickness, a surrogate marker of atherosclerosis, indeed demonstrated that levels of inflammatory markers in the serum correlated with the subclinical atherosclerotic disease score in patients with RA. ${ }^{33}$ A more detailed analysis of carotid arteries by ultrasonography pointed to more unstable plaques in patients with RA with active disease.$^{34} \mathrm{CT}$ angiography analysis confirmed the presence of more vulnerable plaques in coronary arteries of patients with RA with more active disease. ${ }^{14}$ Furthermore, increased aortic stiffness (which is a consequence of dysfunctional endothelium) was found in patients with RA with elevated CRP levels indicative of systemic inflammation. ${ }^{35}$ Clinical data further confirmed that elevated inflammatory markers as well as increased disease activity were associated with increased risk of acute coronary events in patients with RA. ${ }^{36}$ Interestingly, the risk of myocardial infarction in RA has not been associated with disease activity but with CRP level. ${ }^{37}$ Taken together, these published data suggest that chronic high-grade inflammation is a key factor promoting atherosclerosis and coronary artery disease in patients with RA.

\section{Inflammation and non-ischaemic heart diseases}

In contrast to the well-described contribution of systemic inflammation to atherosclerosis, its role in the development of non-ischaemic heart disease is less well characterised. Active inflammatory processes in the heart may lead to excessive myocardial fibrosis causing stiffening of the ventricles and thus contribute to systolic and diastolic dysfunctions and to cardiac arrhythmia. Cardiac MRI and PET-CT data indeed confirmed a correlation between RA disease activity and increased myocardial inflammation and fibrosis. ${ }^{78}$ Structural changes in the myocardium observed with cardiac MRI also correlate with diagnostic markers of systemic inflammation. ${ }^{38}$ Furthermore, high disease activity and elevated CRP levels were associated with increased prevalence of diastolic heart failure. ${ }^{39} \mathrm{~A}$ recent large cohort study confirmed that high disease activity and elevated inflammatory markers were associated with an increased risk of non-ischaemic heart failure (including those with preserved ejection fraction) in patients with RA. ${ }^{16}$ Consistent with these observations, patients with RA with low disease activity showed unaffected structure and function of the cardiac muscle. ${ }^{40}{ }^{41}$ One would expect that high-grade systemic inflammation is responsible for the end-stage heart failure, the non-ischaemic sudden cardiac death and the overall cardiac mortality in RA, but the supporting clinical data are not yet available.

\section{IMPACT OF MEDICATION ON DEVELOPMENT OF HEART DISEASE IN RA}

Disease-modifying antirheumatic drugs (DMARDs) represent a major therapeutic option in RA. Conventional 
synthetic disease-modifying antirheumatic drugs (csDMARDs) represent chemical, synthetic, non-selective drugs, such as hydroxychloroquine, methotrexate, leflunomide and sulfasalazine. Furthermore, corticosteroids and non-steroidal anti-inflammatory medications are also commonly used in RA. In contrast to csDMARDs, biologic disease-modifying antirheumatic drugs (bDMARDs) block specific inflammatory mediators. Anti-TNF- $\alpha$ inhibitors represent the most common bDMARDs in RA therapy. In some cases, patients with RA receive other biological drugs that suppress IL-6 signalling, $\mathrm{T}$ and $\mathrm{B}$ cells or targeted synthetic disease-modifying antirheumatic drugs (tsDMARDs), which inhibit Janus kinase (JAK) activity. Although long-term treatment with these immunosuppressive drugs is not always beneficial for cardiovascular outcomes, it is believed that improved medications and 'treat-to-target' approaches are the main reasons for the decline in cardiovascular mortality among patients with RA in recent years. ${ }^{4} 18$

It should be noted that classical cardioprotective medications, such as a low-dose aspirin, statins, folic acid, ACE inhibitors and angiotensin II receptor blockers have also been introduced to the prevention and therapy of cardiovascular diseases in $\mathrm{RA},{ }^{18}$ and recent data confirmed the cardioprotective effect of statins in patients with RA. ${ }^{42}$

\section{csDMARDs and cardiovascular diseases}

csDMARDs represent the first line of pharmacological therapy in RA. Antimalarial drugs (particularly hydroxychloroquine) and methotrexate are cardioprotective in most studies. ${ }^{43-45}$ Hydroxychloroquine may also inhibit platelet aggregation and the thrombogenic effects of antiphospholipid antibodies. ${ }^{46}$ In some cases, however, antimalarials can induce cardiomyopathies in patients with RA. ${ }^{47}$ The vascular effects of methotrexate may be somewhat controversial. Methotrexate itself increases the production of the proatherogenic homocysteine. Homocysteine is toxic for endothelial cells and stimulates LDL oxidation. On the other hand, methotrexate controls systemic inflammation and thus may exert beneficial cardiovascular effects. ${ }^{1844}{ }^{48}$ In some studies, methotrexate reduced rather than aggravated cardiovascular risk. $^{434}$ As a mode of action, methotrexate improves reverse cholesterol transport and restores inflammationrelated impairment of cholesterol efflux in RA. In a large meta-analysis, methotrexate reduced the risk of major adverse cardiovascular events. ${ }^{44}$ Interestingly, in a recent trial in patients without RA with cardiovascular disease, methotrexate was unable to prevent cardiovascular events. ${ }^{49}$ Thus, the beneficial effects of methotrexate may be observed under inflammatory conditions only. Less data are available regarding the possible cardiovascular effects of other csDMARDs. In a case-control study, sulfasalazine treatment for RA was associated with a lower cardiovascular risk compared with patients with RA who never used sulfasalazine, hydroxychloroquine or methotrexate ${ }^{50}$ Furthermore, treatment with leflunomide was associated with a significantly lower rate of myocardial infarction in comparison with patients with RA receiving other medications. ${ }^{45}$ In contrast to other csDMARDs, leflunomide may, however, increase blood pressure and aggravate hypertension..$^{51}$

csDMARDs can be supplemented by corticosteroid therapy, and in case of exacerbation of pain, patients with RA also receive non-steroidal anti-inflammatory drugs (primarily COX-2 inhibitors). These drugs increase the risk of cardiovascular events. ${ }^{18}{ }^{44}$ Of note, even shortterm (1-year) treatment with corticosteroids in patients with new-onset RA significantly increased the risk of nonischaemic heart failure. ${ }^{16}$ It should be acknowledged that patients with RA taking non-steroidal anti-inflammatory drugs often show high disease activity. Therefore, we cannot exclude that the increased risk is due to high inflammatory status of these patients, rather than the atherogenic potential of these medications.

\section{Anti-TNF- $\alpha$ therapy and heart disease}

TNF- $\alpha$ is considered the predominant cytokine governing inflammation in RA. The fusion protein of TNF- $\alpha$ receptors linked to the Fc region of human antibody (etanercept) and chimeric (infliximab), fully human (adalimumab and golimumab) or modified human (certolizumab-pegol) anti-TNF- $\alpha$ antibodies represent clinically used TNF- $\alpha$ antagonists in RA that can effectively reduce inflammation and joint damage. It has been hypothesised that anti-TNF- $\alpha$ treatment could be useful to treat other inflammation-mediated diseases including heart disease. Elevated plasma TNF- $\alpha$ levels were found in patients with chronic heart failure and were associated with increased mortality ${ }^{52}$ Mouse data confirmed that overproduction of TNF- $\alpha$ in the heart induced myocardial inflammation, remodelling, fibrosis and heart failure.$^{53}$ Unexpectedly, clinical trials failed to confirm the beneficial effect of anti-TNF- $\alpha$ antagonists etanercept and infliximab on patients with chronic heart failure ${ }^{5455}$ In fact, a higher dose of infliximab $(10 \mathrm{mg} / \mathrm{kg})$ in New York Heart Association class III or IV patients contributed to the worsening of heart failure and to the reduction of lifespan. ${ }^{55}$ Consequently, anti-TNF- $\alpha$ therapy is currently not recommended for patients with heart failure.

In light of these data, the question was raised whether anti-TNF- $\alpha$ therapy could be harmful for patients with RA by promoting heart failure. Results of clinical studies provided an ambiguous answer. ${ }^{56}$ In general, most data reported unchanged or slightly reduced risk of heart failure and improved survival of patients with RA receiving anti-TNF- $\alpha$ treatment. ${ }^{57-59}$ A more focused subgroup analysis showed that anti-TNF- $\alpha$ therapy might be beneficial for women ${ }^{58}$ and younger patients with $\mathrm{RA},{ }^{59}$ but in an elderly population, it might exacerbate heart failure and reduce survival. ${ }^{60}$

Cardiovascular status might be a critical factor for the outcomes of anti-TNF- $\alpha$ therapy. A growing body of evidence suggests that blocking TNF- $\alpha$ signalling could be helpful for patients with RA with good overall health status and unaffected cardiac function. It has 
been shown that infliximab improved heart function in patients with RA with preserved left ventricular function. ${ }^{61}$ Furthermore, a recent large-scale clinical study indicated that anti-TNF- $\alpha$ therapy in patients with RA effectively reduced the incidence of acute coronary syndrome. ${ }^{62}$ These beneficial effects were, however, not observed for postischaemic events. ${ }^{63}$ It should be mentioned that anti-TNF- $\alpha$ therapy in patients with RA is associated with a significantly increased risk of developing hypertension. ${ }^{64}$

Dosing and duration of anti-TNF- $\alpha$ therapy represent factors that might be decisive for cardioprotection versus cardiotoxicity. It should be noted that patients with RA usually receive doses of etanercept ( $50 \mathrm{mg}$ once weekly) or infliximab $(3 \mathrm{mg} / \mathrm{kg})$ that were safe for patients with heart failure. Only a fraction of patients with RA nonresponding to a standard dose of infliximab receive this drug at $10 \mathrm{mg} / \mathrm{kg}$. In contrast to etanercept and infliximab, other TNF- $\alpha$ inhibitors were not tested in patients with heart failure. Recent data demonstrated, for example, a decreased incidence of hospitalisation due to heart failure in patients with RA treated with adalimumab. ${ }^{65}$ Further studies are, however, needed to prove its beneficial effects also in patients with RA with serious heart failure.

In summary, anti-TNF- $\alpha$ therapies effectively suppress inflammation and prevent progression of RA and thereby reduce the risk of cardiovascular episodes. In patients with RA with established heart failure, the treatment does not improve cardiac function and, in some cases, might worsen it (figure 2). It seems that in patients with RA without heart failure, TNF- $\alpha$ increases the risk of cardiovascular disorders by promoting systemic inflammation. In the failing heart, instead, TNF- $\alpha$ might play a cardioprotective role, but the underlaying mechanisms remain unknown.

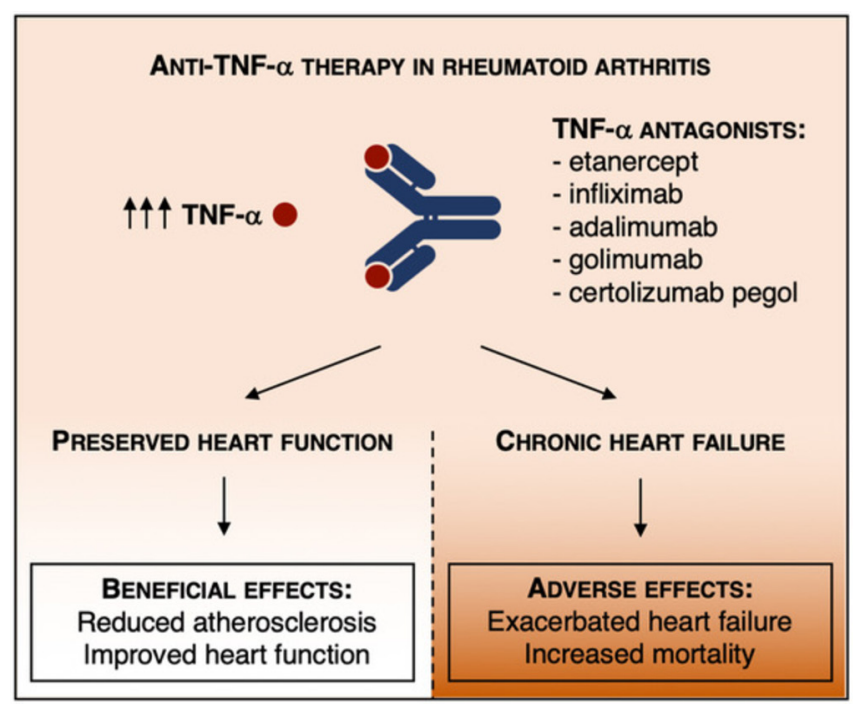

Figure 2 Dual role of anti-TNF- $\alpha$ therapy on cardiovascular risk in rheumatoid arthritis. TNF- $\alpha$, tumour necrosis factoralpha.

\section{OTHER BDMARDS AND TSDMARDS AND HEART DISEASE}

In addition to TNF- $\alpha$, IL-6 represents another proinflammatory cytokine targeted in RA. In the context of the development of major adverse cardiovascular events, the IL-6 receptor inhibitor tocilizumab was shown to be a safe alternative for the TNF- $\alpha$ antagonist etanercept. ${ }^{66}$

Abatacept and rituximab represent another class of bDMARDs, which target antigens on the surface of dendritic cells (CD80/86) and B cells (CD20), respectively. $\mathrm{T}$ cell costimulation inhibitor abatacept is prescribed to patients with RA with a worse cardiovascular profile; however, it does not affect the risk of developing heart failure compared with etanercept. ${ }^{67}$ Rituximab is a humanised chimeric anti-CD20 monoclonal antibody preventing B cell activation. Rituximab was shown to improve vascular pathophysiology in RA. ${ }^{68}$ In clinical trials, rituximab showed a cardiovascular safety profile comparable to anti-TNF- $\alpha$ treatments. ${ }^{69}$

Some patients with RA receive tsDMARDs JAK inhibitors tofacitinib or baricitinib. Both JAK inhibitors have been shown to worsen the plasma lipid profile; however, data from clinical studies and databases do not suggest an increased cardiovascular risk in patients with RA treated with these drugs. ${ }^{70}$ It should be mentioned that statins can effectively reverse dyslipidaemia in patients with RA treated with tofacitinib. ${ }^{72}$

In summary, all these drugs seem to represent safe options for patients with RA with no serious adverse effects on the cardiovascular system. On the other hand, despite of their anti-inflammatory properties, no marked beneficial cardioprotective effects have been observed for any class of these medications.

\section{PERSPECTIVES}

In recent years, improved treatment strategies, such as the treat-to-target approach, successfully reduced cardiovascular risk in RA. Patients with incidental arthritis and low disease activity do not need additional non-conventional treatments. However, despite advanced antirheumatic medication, some patients with RA still show high disease activity. Future studies should be more focused on targeted, cardioprotective therapies tailored for these patients with RA with high disease activity and those with established heart failure. Achievement of these goals requires a better understanding of RA-related pathophysiological processes promoting heart failure. Clinical studies have already shed some light onto the pathogenesis of heart diseases in RA, but the fundamental cellular and molecular mechanisms of pathogenesis remain obscure. Additional strategies should focus on preclinical experimental studies using animal models and ex vivo human tissues. Currently, experimental research seems to be under-represented in cardiorheumatology. In the future, a balanced cooperation between clinical and experimental research will be required to identify new therapeutic targets and eventually to develop successful cardioprotective therapies for patients with RA. 
Contributors Conceptualisation: PB. Writing: PB and ZS.

Funding The authors have not declared a specific grant for this research from any funding agency in the public, commercial or not-for-profit sectors.

Competing interests None declared.

Patient consent for publication Not required

Provenance and peer review Commissioned; externally peer reviewed.

Open access This is an open access article distributed in accordance with the Creative Commons Attribution Non Commercial (CC BY-NC 4.0) license, which permits others to distribute, remix, adapt, build upon this work non-commercially, and license their derivative works on different terms, provided the original work is properly cited, appropriate credit is given, any changes made indicated, and the use is non-commercial. See: http://creativecommons.org/licenses/by-nc/4.0/.

ORCID iD

Przemysław Błyszczuk http://orcid.org/0000-0003-2521-3232

\section{REFERENCES}

1 Avina-Zubieta JA, Thomas J, Sadatsafavi M, et al. Risk of incident cardiovascular events in patients with rheumatoid arthritis: a metaanalysis of observational studies. Ann Rheum Dis 2012;71:1524-9.

2 Aviña-Zubieta JA, Choi HK, Sadatsafavi M, et al. Risk of cardiovascular mortality in patients with rheumatoid arthritis: a metaanalysis of observational studies. Arthritis Rheum 2008;59:1690-7.

3 Lacaille D, Avina-Zubieta JA, Sayre EC, et al. Improvement in 5 -year mortality in incident rheumatoid arthritis compared with the general population-closing the mortality gap. Ann Rheum Dis 2017;76:1057-63.

4 Provan SA, Lillegraven S, Sexton J, et al. Trends in all-cause and cardiovascular mortality in patients with incident rheumatoid arthritis: a 20-year follow-up matched case-cohort study. Rheumatology 2019;26:kez371

5 Mavrogeni S, Dimitroulas T, Sfikakis PP, et al. Heart involvement in rheumatoid arthritis: multimodality imaging and the emerging role of cardiac magnetic resonance. Semin Arthritis Rheum 2013;43:314-24.

6 Ntusi NAB, Piechnik SK, Francis JM, et al. Diffuse myocardial fibrosis and inflammation in rheumatoid arthritis: insights from CMR T1 mapping. JACC Cardiovasc Imaging 2015;8:526-36.

7 Amigues I, Tugcu A, Russo C, et al. Myocardial inflammation, measured using 18-Fluorodeoxyglucose positron emission tomography with computed tomography, is associated with disease activity in rheumatoid arthritis. Arthritis Rheumatol 2019;71:496-506.

8 Rudominer RL, Roman MJ, Devereux RB, et al. Independent association of rheumatoid arthritis with increased left ventricular mass but not with reduced ejection fraction. Arthritis Rheum 2009:60:22-9.

9 Cioffi G, Viapiana O, Ognibeni F, et al. Prevalence and factors related to left ventricular systolic dysfunction in asymptomatic patients with rheumatoid arthritis. A prospective tissue Doppler echocardiography study. Herz 2015;40:989-96.

10 Aslam F, Bandeali SJ, Khan NA, et al. Diastolic dysfunction in rheumatoid arthritis: a meta-analysis and systematic review. Arthritis Care Res 2013;65:534-43.

11 Corrao S, Messina S, Pistone G, et al. Heart involvement in rheumatoid arthritis: systematic review and meta-analysis. Int $J$ Cardiol 2013;167:2031-8.

12 Kerekes G, Soltész P, Nurmohamed MT, et al. Validated methods for assessment of subclinical atherosclerosis in rheumatology. Nat Rev Rheumatol 2012;8:224-34.

13 Amigues I, Russo C, Giles JT, et al. Myocardial microvascular dysfunction in rheumatoid arthritisquantitation by (13)N-ammonia positron emission tomography/computed tomography. Circ Cardiovasc Imaging 2019;12:e007495.

14 Karpouzas GA, Malpeso J, Choi T-Y, et al. Prevalence, extent and composition of coronary plaque in patients with rheumatoid arthritis without symptoms or prior diagnosis of coronary artery disease. Ann Rheum Dis 2014;73:1797-804.

15 Maradit-Kremers H, Crowson CS, Nicola PJ, et al. Increased unrecognized coronary heart disease and sudden deaths in rheumatoid arthritis: a population-based cohort study. Arthritis Rheum 2005;52:402-11.

16 Mantel Ängla, Holmqvist M, Andersson DC, et al. Association between rheumatoid arthritis and risk of ischemic and nonischemic heart failure. J Am Coll Cardiol 2017;69:1275-85.

17 Davis JM, Roger VL, Crowson CS, et al. The presentation and outcome of heart failure in patients with rheumatoid arthritis differs from that in the general population. Arthritis Rheum 2008:58:2603-11.

18 Agca R, Heslinga SC, Rollefstad S, et al. EULAR recommendations for cardiovascular disease risk management in patients with rheumatoid arthritis and other forms of inflammatory joint disorders: 2015/2016 update. Ann Rheum Dis 2017;76:17-28.

19 Lindhardsen J, Ahlehoff O, Gislason GH, et al. The risk of myocardial infarction in rheumatoid arthritis and diabetes mellitus: a Danish nationwide cohort study. Ann Rheum Dis 2011;70:929-34.

20 Agca R, Hopman LHGA, Laan KJC, et al. Cardiovascular event risk in rheumatoid arthritis compared with type 2 diabetes: a 15-year longitudinal study. J Rheumatol 2019:jrheum.180726.

21 McCoy SS, Crowson CS, Maradit-Kremers H, et al. Longterm outcomes and treatment after myocardial infarction in patients with rheumatoid arthritis. J Rheumatol 2013;40:605-10.

22 Van Doornum S, Brand C, King B, et al. Increased case fatality rates following a first acute cardiovascular event in patients with rheumatoid arthritis. Arthritis Rheum 2006;54:2061-8.

23 Chauhan K, Ackerman MJ, Crowson CS, et al. Population-based study of QT interval prolongation in patients with rheumatoid arthritis. Clin Exp Rheumatol 2015;33:84-9.

24 Turk SA, Heslinga SC, Dekker J, et al. The relationship between cardiac conduction times, cardiovascular risk factors, and inflammation in patients with early arthritis. J Rheumatol 2017;44:580-6.

25 Nicola PJ, Crowson CS, Maradit-Kremers H, et al. Contribution of congestive heart failure and ischemic heart disease to excess mortality in rheumatoid arthritis. Arthritis Rheum 2006;54:60-7.

26 Gonzalez A, Maradit Kremers H, Crowson CS, et al. Do cardiovascular risk factors confer the same risk for cardiovascular outcomes in rheumatoid arthritis patients as in non-rheumatoid arthritis patients? Ann Rheum Dis 2008;67:64-9.

27 Baghdadi LR, Woodman RJ, Shanahan EM, et al. The impact of traditional cardiovascular risk factors on cardiovascular outcomes in patients with rheumatoid arthritis: a systematic review and metaanalysis. PLoS One 2015;10:e0117952.

28 Myasoedova E, Crowson CS, Kremers HM, et al. Lipid paradox in rheumatoid arthritis: the impact of serum lipid measures and systemic inflammation on the risk of cardiovascular disease. Ann Rheum Dis 2011;70:482-7.

29 Escalante A, Haas RW, del Rincón I. Paradoxical effect of body mass index on survival in rheumatoid arthritis: role of comorbidity and systemic inflammation. Arch Intern Med 2005;165:1624-9.

30 Goodson NJ, Symmons DPM, Scott DGI, et al. Baseline levels of Creactive protein and prediction of death from cardiovascular disease in patients with inflammatory polyarthritis: a ten-year followup study of a primary care-based inception cohort. Arthritis Rheum 2005;52:2293-9.

31 Myasoedova E, Chandran A, Ilhan B, et al. The role of rheumatoid arthritis $(\mathrm{rA})$ flare and cumulative burden of RA severity in the risk of cardiovascular disease. Ann Rheum Dis 2016;75:560-5.

32 Arts EEA, Fransen J, Den Broeder AA, et al. Low disease activity (DAS28 $\leq 3.2$ ) reduces the risk of first cardiovascular event in rheumatoid arthritis: a time-dependent COX regression analysis in a large cohort study. Ann Rheum Dis 2017;76:1693-9.

33 Vázquez-Del Mercado M, Nuñez-Atahualpa L, Figueroa-Sánchez $\mathrm{M}$, et al. Serum levels of anticyclic citrullinated peptide antibodies, interlum levels of Anticyclic citrullinated peptide antibodies, interleukin-6, tumor necrosis factor- $\alpha$, and C-reactive protein are associated with increased carotid intima-media thickness: a crosssectional analysis of a cohort of rheumatoid arthritis patients without cardiovascular risk fReactive protein are associated with increased carotid intima-media thickness: a cross-sectional analysis of a cohort of rheumatoid arthritis patients without cardiovascular risk factors. Biomed Res Int 2015;2015:1-10.

34 Semb AG, Rollefstad S, Provan SA, et al. Carotid plaque characteristics and disease activity in rheumatoid arthritis. $J$ Rheumatol 2013;40:359-68.

35 Galarraga B, Khan F, Kumar P, et al. Etanercept improves inflammation-associated arterial stiffness in rheumatoid arthritis. Rheumatology 2009;48:1418-23.

36 Mantel Ängla, Holmqvist M, Nyberg F, et al. Risk factors for the rapid increase in risk of acute coronary events in patients with new-onset rheumatoid arthritis: a nested case-control study. Arthritis Rheumatol 2015;67:2845-54.

37 Meissner Y, Zink A, Kekow J, et al. Impact of disease activity and treatment of comorbidities on the risk of myocardial infarction in rheumatoid arthritis. Arthritis Res Ther 2016;18.

38 Mavrogeni S, Karabela G, Stavropoulos E, et al. Imaging patterns of heart failure in rheumatoid arthritis evaluated by cardiovascula magnetic resonance. Int J Cardiol 2013;168:4333-5. 
39 Schau T, Gottwald M, Arbach O, et al. Increased prevalence of diastolic heart failure in patients with rheumatoid arthritis correlates with active disease, but not with treatment type. $J$ Rheumatol 2015:42:2029-37.

40 Bradham W, Ormseth MJ, Elumogo C, et al. Absence of fibrosis and inflammation by cardiac magnetic resonance imaging in rheumatoid arthritis patients with low to moderate disease activity. J Rheumatol 2018;45:1078-84.

41 Targońska-Stępniak B, Biskup M, Biskup W, et al. Diastolic dysfunction in rheumatoid arthritis patients with low disease activity. Clin Rheumatol 2019;38:1131-7.

42 Kitas GD, Nightingale P, Armitage J, et al. A multicenter, randomized, placebo-controlled trial of atorvastatin for the primary prevention of cardiovascular events in patients with rheumatoid arthritis. Arthritis Rheumatol 2019;71:1437-49.

43 Marks JL, Edwards CJ. Protective effect of methotrexate in patients with rheumatoid arthritis and cardiovascular comorbidity. Ther Adv Musculoskelet Dis 2012;4:149-57.

44 Roubille C, Richer V, Starnino T, et al. The effects of tumour necrosis factor inhibitors, methotrexate, non-steroidal anti-inflammatory drugs and corticosteroids on cardiovascular events in rheumatoid arthritis, psoriasis and psoriatic arthritis: a systematic review and meta-analysis. Ann Rheum Dis 2015;74:480-9.

45 Suissa S, Bernatsky S, Hudson M. Antirheumatic drug use and the risk of acute myocardial infarction. Arthritis Rheum 2006;55:531-6.

46 Espinola RG, Pierangeli SS, Gharavi AE, et al. Hydroxychloroquine reverses platelet activation induced by human IgG antiphospholipid antibodies. Thromb Haemost 2002;87:518-22.

47 Tselios K, Deeb M, Gladman DD, et al. Antimalarial-induced cardiomyopathy: a systematic review of the literature. Lupus 2018:27:591-9.

48 Atzeni F, Turiel M, Caporali R, et al. The effect of pharmacological therapy on the cardiovascular system of patients with systemic rheumatic diseases. Autoimmun Rev 2010;9:835-9.

49 Ridker PM, Everett BM, Pradhan A, et al. Low-Dose methotrexate for the prevention of atherosclerotic events. N Engl J Med 2019;380:752-62.

50 van Halm VP, Nurmohamed MT, Twisk JWR, et al. DiseaseModifying antirheumatic drugs are associated with a reduced risk for cardiovascular disease in patients with rheumatoid arthritis: a case control study. Arthritis Res Ther 2006;8:R151.

51 Baker JF, Sauer B, Teng C-C, et al. Initiation of disease-modifying therapies in rheumatoid arthritis is associated with changes in blood pressure. J Clin Rheumatol 2018;24:203-9.

52 Rauchhaus M, Doehner W, Francis DP, et al. Plasma cytokine parameters and mortality in patients with chronic heart failure. Circulation 2000;102:3060-7.

53 Sivasubramanian N, Coker ML, Kurrelmeyer KM, et al. Left ventricular remodeling in transgenic mice with cardiac restricted overexpression of tumor necrosis factor. Circulation 2001;104:826-31.

54 Mann DL, McMurray JJV, Packer M, et al. Targeted anticytokine therapy in patients with chronic heart failure: results of the randomized etanercept worldwide evaluation (renewal). Circulation 2004;109:1594-602.

55 Chung ES, Packer M, Lo KH, et al. Randomized, double-blind, placebo-controlled, pilot trial of infliximab, a chimeric monoclonal antibody to tumor necrosis factor-alpha, in patients with moderate-to-severe heart failure: results of the anti-TNF therapy against congestive heart failure (attach) trial. Circulation 2003;107:3133-40.
56 Szekanecz Z, Kerekes G, Soltész P. Vascular effects of biologic agents in RA and spondyloarthropathies. Nat Rev Rheumatol 2009;5:677-84.

57 Solomon DH, Rassen JA, Kuriya B, et al. Heart failure risk among patients with rheumatoid arthritis starting a TNF antagonist. Ann Rheum Dis 2013;72:1813-8.

58 Jacobsson LTH, Turesson C, Nilsson J-A, et al. Treatment with TNF blockers and mortality risk in patients with rheumatoid arthritis. Ann Rheum Dis 2007;66:670-5.

59 Al-Aly Z, Pan H, Zeringue A, et al. Tumor necrosis factor- $\alpha$ blockade, cardiovascular outcomes, and survival in rheumatoid arthritis. Trans/ Res 2011;157:10-18.

60 Setoguchi S, Schneeweiss S, Avorn J, et al. Tumor necrosis factor- $\alpha$ antagonist use and heart failure in elderly patients with rheumatoid arthritis. Am Heart J 2008;156:336-41.

61 Kotyla PJ, Owczarek A, Rakoczy J, et al. Infliximab treatment increases left ventricular ejection fraction in patients with rheumatoid arthritis: assessment of heart function by echocardiography, endothelin 1, interleukin 6, and NT-pro brain natriuretic peptide. $J$ Rheumatol 2012;39:701-6.

62 Ljung L, Askling J, Rantapää-Dahlqvist S, et al. The risk of acute coronary syndrome in rheumatoid arthritis in relation to tumour necrosis factor inhibitors and the risk in the general population: a national cohort study. Arthritis Res Ther 2014;16.

63 Low ASL, Symmons DPM, Lunt M, et al. Relationship between exposure to tumour necrosis factor inhibitor therapy and incidence and severity of myocardial infarction in patients with rheumatoid arthritis. Ann Rheum Dis 2017;76:654-60.

64 Zhao Q, Hong D, Zhang Y, et al. Association between anti-TNF therapy for rheumatoid arthritis and hypertension: a meta-analysis of randomized controlled trials. Medicine 2015;94:e731.

65 Harrold LR, Griffith J, Zueger P, et al. Long-Term, real-world safety of adalimumab in rheumatoid arthritis: analysis of a prospective USBased registry. J Rheumatol 2019:jrheum.190260.

66 Giles JT, Sattar N, Gabriel S, et al. Cardiovascular safety of tocilizumab versus etanercept in rheumatoid arthritis: a randomized controlled trial. Arthritis Rheumatol 2019. doi:10.1002/art.41095. [Epub ahead of print: 30 Aug 2019].

67 Generali E, Carrara G, Kallikourdis M, et al. Risk of hospitalization for heart failure in rheumatoid arthritis patients treated with etanercept and abatacept. Rheumatol Int 2019;39:239-43.

68 Kerekes $\mathrm{G}$, Soltész P, Dér $\mathrm{H}$, et al. Effects of rituximab treatment on endothelial dysfunction, carotid atherosclerosis, and lipid profile in rheumatoid arthritis. Clin Rheumatol 2009;28:705-10.

69 Harrold LR, Reed GW, Magner R, et al. Comparative effectiveness and safety of rituximab versus subsequent anti-tumor necrosis factor therapy in patients with rheumatoid arthritis with prior exposure to anti-tumor necrosis factor therapies in the United States Corrona registry. Arthritis Res Ther 2015;17.

70 Charles-Schoeman C, Wicker P, Gonzalez-Gay MA, et al. Cardiovascular safety findings in patients with rheumatoid arthritis treated with tofacitinib, an oral Janus kinase inhibitor. Semin Arthritis Rheum 2016;46:261-71.

71 Taylor PC, Weinblatt ME, Burmester GR, et al. Cardiovascular safety during treatment with Baricitinib in rheumatoid arthritis. Arthritis Rheumatol 2019;71:1042-55.

72 McInnes IB, Kim H-Y, Lee S-H, et al. Open-Label tofacitinib and double-blind atorvastatin in rheumatoid arthritis patients: a randomised study. Ann Rheum Dis 2014;73:124-31. 